\title{
Explore the Relationship between Impulse Control, Diabetes Specific Self- Efficacy and Diabetes Management among Young Adults with Diabetes Mellitus
}

\author{
Ambareesh Patil ${ }^{1}$, Deelip S Natekar ${ }^{2}$, Utalbasha Dhandargi ${ }^{3}$ \\ ${ }^{1}$ M.Sc Nursing 2nd Year, ${ }^{2}$ Principal, ${ }^{3}$ Professor, Department of Community Health Nursing, \\ Shri B.V.V.S Sajjalashree Institute of Nursing Sciences, Navanagar, Bagalkot, Karnataka, India \\ Corresponding Author: Utalbasha Dhandargi
}

DOI: https://doi.org/10.52403/ijshr.20220114

\begin{abstract}
Introduction: Diabetes Mellitus is one of most commonly accepted diseases in Indian society affecting one in four adults. Diabetes is a group of diseases that results increase in the level of sugar in the blood. Diabetes is no more an old age disease ${ }^{1}$. Currently adults just above 20 years of age are reported with this menace disrupting the daily life and Health.

Objective: The aim of the study was to explore the relationship among impulse control, diabetes specific self- efficacy and diabetes management among young adults with Diabetes Mellitus.

Methods: Cross sectional Research design was used with a sample of 91 young adults selected by convenient sampling technique at Tulsigirish Diabetic care hospital in Bagalkot District, Karnataka. Data collection was done with 4 instruments: Structured questionnaire to assess socio demographic profile, Self control scale, Diabetes specific self efficacy scale and Diabetes self management questionnaire scale. The sample size was calculated using G-Power 3.1.9.4 software.

Results: The Mean age of sample was $30.27 \pm$ 6.479 years with the minimum age; 18 years and maximum age; 40 years. The mean Duration of DM among sample was $24.90 \pm 25.9$ months The Mean Impulse control scores was $37.55 \pm$ 5.576 with the minimum score 10 and maximum score 50. The Mean self efficacy score was $50.93 \pm 10$ and the Mean Diabetes self management score was $25.45 \pm 4.382$. The mean Dietary control score was $7.43 \pm 2.011$. The
\end{abstract}

mean Medical Adherence score was 3.74 \pm 1.315 . The mean Blood Glucose Monitoring score was $4.27 \pm 2.289$. The mean Physical Activity score was $3.83 \pm 1.969$. The mean Physician Contact score was 5.56 \pm 1.3013 . The mean overall DSM score was $0.64 \pm 0.753$. A significant association was found between impulse control and Diabetes management. A significant association was found between Educational status $\left(\mathrm{X}^{2}=8.954, \mathrm{P}<0.05\right)$, Marital status $\left(\mathrm{X}^{2}=6.614, \mathrm{P}<0.05\right)$, Habit of consuming alcohol $\quad\left(X^{2}=9.291, \quad P<0.05\right)$ and Diabetes Management among Young adults.

Conclusion: The findings revealed that respondents had Good Impulse control, Average Diabetes self efficacy and Average Diabetes self management among young adults with Diabetes Mellitus.

Key words: Young adults, Impulse control, Diabetes specific self efficacy, Diabetes self management.

\section{INTRODUCTION}

Diabetes not only disrupts the physical and physiological health but also devastates mental well being and quality of life of the sufferer. Adhering to WHO definition of health, a person can be considered healthy not merely in the absence of disease. A person with diabetes can be healthy with appropriate management and keeping the blood sugar levels with normal range ${ }^{1}$. 
India has an estimated 77 million people with diabetes, a country that is already facing challenges such as malnutrition, poverty and socioeconomic burden caused by communicable diseases. The main risk factors for the high prevalence of diabetes include high familial aggregation, obesity, insulin resistance and metabolic syndrome, lifestyle changes such as increased consumption of saturated fats, sugars and sedentary behavior as a result of urbanization, and gestational diabetes ${ }^{2}$.

Diabetes Mellitus is a condition with chronically increased blood sugar level as result of inability of pancreas in maintaining blood sugar level. In certain autoimmune condition the immune system attacks and destroys cells in the pancreas. Type $1 \mathrm{DM}$ is a result of autoimmune disease ${ }^{2}$.

DM is a chronic disease, once acquired it remains throughout life. Hence the best strategy to lead a good quality life is to maintain the blood sugar level in its optimum range. This maintenance needs an appropriate and strict adherence to treatment regimen. But adherence needs balance of many psychological aspects like impulse control, self efficacy, good sleep etc ${ }^{2}$.

According to IDF Diabetes Atlas ninth edition-Diabetes is one among the fastest growing health challenges of $21^{\text {st }}$ century with the number of adults living with diabetes having more than tripled over past 20 years ${ }^{3}$.

According to WHO Impulse control is a condition in which a person has trouble controlling emotions or behaviors and often the behaviors violate the rights of others or conflict with societal norms and the law ${ }^{4}$.

Self-efficacy is defined as the ability of individual to perform an action successfully or her/his perception of being able to control events. Self-efficacy impacts compliance with treatment and, therefore, plays a role in the clinical outcome. Increase in the self-efficacy of the individual increases the compliance with the recommended treatment in chronic disease. It also reflects one's ability to adopt behavioral changes for better self-care abilities. Therefore, evaluation of selfefficacy of the diabetic individuals helps in the selection of suitable self-care interventions ${ }^{5}$.

The prevalence of type 2 diabetes in adolescents and young adults is dramatically increasing. The major predisposing risk factors are obesity, family history, and sedentary lifestyle. Onset of diabetes at a younger age (defined here as up to age 40 years) is associated with longer disease exposure and increased risk for complications. Young-onset type 2 diabetes also affects more individuals of working age, accentuating the adverse societal effects of the disease. Furthermore, a more aggressive disease phenotype, leading to premature development of complications, with adverse effects on quality of life and unfavorable effects on long-term outcomes, raising the possibility of a future public health catastrophe ${ }^{6}$.

Karnataka is at $6^{\text {th }}$ place with a prevalence of $7.5 \%$ Diabetes in India. But it is among the top three when it comes Tamil Nadu (10.4\%) in diabetes prevalence because people in north Karnataka consume coarse cereals a lot unlike Tamil Nadu where rice is the staple diet. But the huge number of pre-diabetic population is a big risk as little change in lifestyle can be made. In Bangalore, $14 \%$ and $21 \%$ people are suffering from diabetes and high blood pressure?

According to IDF Diabetes Atlas $9^{\text {th }}$ Edition-Approximately 463 million adults (20-79 years) were living with diabetes; by 2045 this will rise to 700 million. The proportion of people with type 2 diabetes is increasing in most countries. $79 \%$ of adults with diabetes were living in low-and middle-income countries. More than 1.1 million children and adolescents are living with type 1 diabetes. More than 20 million live births ( 1 in 6 live births) are affected by diabetes during pregnancy. 374 million people are at increased risk of developing type 2 diabetes ${ }^{3}$.

India has an estimated 77 million people with diabetes, which makes it the 
second most affected in the world, after China. One in six people $(17 \%)$ in the world with diabetes is from India. (India's population as calculated in October 2018 was about $17.5 \%$ of the global total.) The number is projected to grow by 2045 to become 134 million as per the International Diabetes Federation ${ }^{8}$.

In 2020, according to the International Diabetes Federation (IDF), 463 million people have diabetes in the world and 88 million people in the Southeast Asia region. Of this 88 million people,77 million belong to India. The prevalence of diabetes in the population is $8.9 \%$, according to the IDF. According to the IDF estimates, India has the second highest number of children with type 1 diabetes after the United States. It also contributes to the largest proportion of incident cases of type 1 diabetes in children in the SEA region. Per the World Health Organization, $2 \%$ of all deaths in India are due to diabetes ${ }^{8}$.

Young adults with Diabetes mellitus portray a greater risk as they have to live for long time with this menace. Diabetes and diabetic retinopathy have been emerging as a significant non-communicable disease leading to ocular morbidity. It is estimated that diabetic retinopathy was responsible for $1.06 \%$ of blindness and $1.16 \%$ of visual impairment globally in $2015^{9}$.

\section{MATERIALS AND METHODS}

Study design: It is a Cross sectional Research design conducted at Tulsigirish Diabetic care hospital in Bagalkot, Karnataka.

Setting of the study: The study was conducted at Tulsigirish Diabetic care Centre in Bagalkot Karnataka. It is a 50 bedded Diabetic care hospital. The recruitment and data collection of participants was carried out in outpatient department.

Participants: The study participants were young adults with Diabetes Mellitus attending OPD of Tulsigirish Diabetic centre Bagalkot. 100 young adults were enrolled for the study. Data of 9 subjects was found incomplete hence; the final sample included in the study was 91 .

\section{Criteria for sample selection:}

Inclusion criteria: The study includes young adults who are:

1. Diagnosed with diabetes management at least 6 months before enrollment in the study.

2. Able to understand/read/ write Kannada or English.

3. Available at the time of data collection.

4. Willing to participate in the study.

Exclusion criteria: The study excludes the young adults who are:

1. Not in a health condition to communicate due to any other comorbidity.

2. Expected to be out of study area at the time of data collection.

3. Mentally challenged and not able to provide data.

4. Enrolled in any other research study as sample that affects the management of Diabetes mellitus.

Sample Size estimation: sample size was estimated using G-Power 3.1.9.4 software considering the following criteria; $\alpha=5 \%$ (0.05), Effect size $=0.15$ and Power of the test $=80 \%(0.80)$. The calculation was done considering linear multiple regression fixed model, with a number of predictors $=2$, power $(1-\mathrm{B}$ error prob $)=0.95$. The calculated sample size was 90, considering the possibility of attritions in the final data the researcher enrolled 100 young adults with DM from OPD, Tulsigirish Diabetic hospital, Bagalkot, as sample. The data collection was done for 100 subjects. 9 subjects had incomplete data hence for final analysis data of 91 young adults was considered.

\section{Description of data collection tools}

The data collection instruments were divided into 4 sections- 


\section{Section 1- Baseline proforma}

It is a structured proforma consisting 15 items regarding baseline data of the subjects.

\section{Scoring/The collected information was coded as follows for data analysis-}

Section 2: Impulse control scale/ selfcontrol scale: It consists of 10 items. The self-control scale aims to assess people's ability to control their impulses, after their emotions, and thoughts.

\section{Scoring -}

where scoring pattern was 1 to $5 ; 1=$ very much like me, $2=$ mostly like me,3=somewhat like me,4=a little like meand $5=$ not at all like me.

The possible score range was 10-50. Participant's responses were summed, with higher scores on the tool were better selfcontrolling. The total Self control scale scores were classified into following categories: 0-10 (very Poor), 11 to 20 (poor) and 21-30 (average), 31-40 (good), 41-50 (excellent).

Section 3: Diabetes specific self-efficacy scale: It is an 8 items scale designed to measure youth's perceived confidence in one's ability to perform self care.

\section{Scoring -}

Where scoring pattern was 1 to 10 , $1=$ not at all confident, $10=$ totally confident.

The possible score range was $8-80$. Participant's responses were summed, with higher scores on the tool were demonstrating better self-management. The total DSSE scores were classified into following categories :< 30 (Poor), 31-60 (average) and >60 (Good).

Section 4: Diabetes self-management questionnaire scale (DSMQ): This scale targets diabetes self-care and assess the behavior control and treatment regimens for Diabetes Mellitus in young adults. It consists of 4 components which include a total of 16items, out of that 5 items on management of glucose, 3 items on physical activity, 4items on dietary control, 3 items on health-care and one item on overall rating on self-care i.e. sum scale.

\section{Scoring -}

Where, scoring pattern was0to3; $3=$ Applies to me very much, $2=$ Applies to me to a considerable degree, $1=$ Applies to me to some degree and $0=$ Does not apply to me.

The possible score range was $0-48$. Participant's responses were summed, with higher scores on the tool were demonstrating better self-management. The total DSMQ scores were classified into following categories: 0-16(Poor), 17-32 (Average) and 33-48 (Good).

\section{Data Collection}

Data collection was done from $16 / 03 / 2021$ to $15 / 05 / 2021$ among 100 young adults with Diabetes mellitus.

\section{Variables of the study \\ Statistical Analysis}

The data was analyzed using SPSS statistical package 28. Repeated measure two way ANOVA and Multiple linear regression analysis were used to determine the association between impulse control, Diabetes specific self efficacy, and Diabetes Management among young adults with diabetes mellitus. Non adjusted odds ratio with 95\% Confidence interval was used to establish the level of association. Spearman rank order correlation was used to determine Correlation between Impulse control and diabetes specific self efficacy. Chi square test was used to determine the association between socio demographic factors and Diabetes management.

\section{Ethical Consideration}

Ethical clearance certificate was obtained from B.V.V.S Sajjalashree Institute of Nursing Sciences, institutional ethical committee. Written consent was obtained from each participant. 
Ambareesh Patil et.al. Explore the relationship between impulse control, diabetes specific self-efficacy and diabetes management among young adults with Diabetes Mellitus

\section{RESULTS}

Table No 1: Description of sample according to Age, Duration of DM and Family monthly income N=91

\begin{tabular}{|l|c|c|c|c|}
\hline \multicolumn{1}{|c|}{ SD Factors } & Mean & $\begin{array}{c}\text { Standard } \\
\text { Deviation }\end{array}$ & $\begin{array}{c}\text { Minimum } \\
\text { value }\end{array}$ & $\begin{array}{c}\text { Maximum } \\
\text { value }\end{array}$ \\
\hline Age in years & 30.27 & 6.479 & 18 & 40 \\
\hline Duration of DM in months & 24.90 & 25.935 & 8 & 192 \\
\hline Family Monthly Income in Rupees & $13,450.55$ & $6,168.493$ & 5,000 & 35,000 \\
\hline
\end{tabular}

Table no 2: Description of Impulse control, diabetes self efficacy and Diabetes self management scores of young adults $\mathrm{N}=91$

\begin{tabular}{|l|c|c|c|c|}
\hline \multicolumn{1}{|c|}{ Characteristics } & Mean & $\begin{array}{c}\text { Standard } \\
\text { Deviation }\end{array}$ & $\begin{array}{c}\text { Minimum } \\
\text { value }\end{array}$ & $\begin{array}{c}\text { Maximum } \\
\text { Value }\end{array}$ \\
\hline Impulse control & 37.55 & 5.576 & 10 & 50 \\
\hline Diabetes specific self efficacy & 50.93 & 10.037 & 8 & 80 \\
\hline Diabetes self management & 25.45 & 4.382 & 00 & 48 \\
\hline
\end{tabular}

The impulse control among sample is further divided; 7 (7.7\%) respondents had Average self control and 54 (59.3\%) respondents had Good self control and 30 (33\%) respondents had excellent self control. None of the respondents had very poor or poor self control.

Most of the subjects, $79(86.8 \%)$ had Average level of DSSE, Whereas $8(8.8 \%)$ respondents had Good and 4 (4.4\%) respondents had poor level of DSSE.

Most of the subjects, 86 (94.5\%) had Average level of DSM. Whereas $4(4.4 \%)$ respondents had Good and 1 (1.1\%) respondents had poor level of DSM.

Domain wise Mean and SD of Diabetes self management; the mean and SD of Dietary control score was $7.43 \pm 2.011$ with the Maximum score was 12 and Minimum score was 0. The mean and SD of Medical Adherence score was $3.74 \pm 1.315$ with the Maximum score was 6 and Minimum score was 0. The mean and SD of Blood Glucose Monitoring score was $4.27 \pm 2.289$ with the Maximum score was 9 and Minimum score was 0 . The mean and SD of Physical Activity score was $3.83 \pm 1.969$ with the Maximum score was 9 and Minimum score was 0. The mean and SD of Physician Contact score was $5.56 \pm 1.3013$ with the Maximum score was 9 and Minimum score was 0 . The mean and SD of overall DSM score was $0.64 \pm 0.753$ with the Maximum score was 3 and Minimum score was 0 .

\begin{tabular}{|c|c|c|c|c|c|c|}
\hline Domains of DSMQ & R square & sum of square & DF & Mean square & $\begin{array}{l}\text { F (t) } \\
\text { value }\end{array}$ & $P$ value (sig) \\
\hline \multirow[t]{2}{*}{ Dietary control } & \multirow[t]{2}{*}{.110} & 39.999 & 1 & 39.999 & 10.978 & .001 \\
\hline & & 324.287 & 89 & 3.644 & & \\
\hline \multirow[t]{2}{*}{ Medical adherence } & \multirow[t]{2}{*}{.052} & 8.060 & 1 & 8.060 & 4.860 & .030 \\
\hline & & 147.610 & 89 & 1.659 & & \\
\hline \multirow[t]{2}{*}{ Blood Glucose Monitoring } & \multirow[t]{2}{*}{.112} & 53.017 & 1 & 53.017 & 11.271 & .001 \\
\hline & & 418.654 & 89 & 4.704 & & \\
\hline \multirow[t]{2}{*}{ Physical activity } & \multirow[t]{2}{*}{.140} & 48.974 & 1 & 48.974 & 14.519 & $<.001$ \\
\hline & & 300.213 & 89 & 3.373 & & \\
\hline \multirow[t]{2}{*}{ Physician contact } & \multirow[t]{2}{*}{.109} & 16.668 & 1 & 16.668 & 10.928 & .001 \\
\hline & & 135.749 & 89 & 1.525 & & \\
\hline \multirow[t]{2}{*}{ Overall } & \multirow[t]{2}{*}{.013} & .657 & 1 & .657 & 1.160 & .284 \\
\hline & & 50.376 & 89 & .566 & & \\
\hline
\end{tabular}

Multiple Linear Regression Analysis was conducted to find the association between Impulse control and Diabetes self management among young adults with Diabetes mellitus. A significant association was found between impulse control with dietary control $(\mathrm{F}=10.978, \mathrm{P}<0.05)$, Medical adherence $\quad(\mathrm{F}=4.860, \quad \mathrm{P}<0.05), \quad$ Blood Glucose Monitoring $(\mathrm{F}=11.271, \mathrm{P}<0.05)$,
Physical activity $(\mathrm{F}=14.519, \quad \mathrm{P}<0.05)$, Physician contact $(\mathrm{F}=10.928, \mathrm{P}<0.05)$ by No significant association was found between overall DSMQ.

Diabetes specific self efficacy and Diabetes self management among young adults with Diabetes mellitus. A significant association was found between Diabetes self efficacy with Physical activity $(\mathrm{F}=18.730$, 
Ambareesh Patil et.al. Explore the relationship between impulse control, diabetes specific self- efficacy and diabetes management among young adults with Diabetes Mellitus

$\mathrm{P}<0.05)$ but No significant association was found between Dietary control, Blood
Glucose Monitoring, Physician contact, Overall DSMQ.

Table No 4: Association between Diabetes specific self efficacy and Diabetes self management among young adults N=91

\begin{tabular}{|c|c|c|c|c|c|c|}
\hline Domains of DSMQ & R square & sum of square & df & Mean square & $\begin{array}{l}\mathbf{F}(\mathbf{t}) \\
\text { value }\end{array}$ & $P$ value (sig) \\
\hline \multirow[t]{2}{*}{ Dietary control } & \multirow[t]{2}{*}{.002} & .749 & 1 & .749 & .183 & .669 \\
\hline & & 363.536 & 89 & 4.085 & & \\
\hline \multirow[t]{2}{*}{ Medical adherence } & \multirow[t]{2}{*}{.002} & .250 & 1 & .250 & .143 & .706 \\
\hline & & 155.421 & 89 & 1.746 & & \\
\hline \multirow[t]{2}{*}{ Blood Glucose Monitoring } & \multirow[t]{2}{*}{.004} & 1.909 & 1 & 1.909 & .362 & .549 \\
\hline & & 469.761 & 89 & 5.278 & & \\
\hline \multirow[t]{2}{*}{ Physical activity } & .174 & 60.709 & 1 & 60.709 & 18.730 & $<.001$ \\
\hline & & 288.478 & 89 & 3.241 & & \\
\hline \multirow[t]{2}{*}{ Physician contact } & .001 & .191 & 1 & .191 & .112 & .739 \\
\hline & & 152.226 & 89 & 1.710 & & \\
\hline \multirow[t]{2}{*}{ Overall } & .001 & .048 & 1 & .048 & .083 & .773 \\
\hline & & 50.985 & 89 & .573 & & \\
\hline
\end{tabular}

Table No 5: Odds Ratio between Impulse Control and Domain Wise DSMQ

\begin{tabular}{|l|c|c|c|}
\hline \multicolumn{1}{|c|}{ Impulse control } & \multirow{2}{*}{$\begin{array}{c}\text { P } \\
\text { Value }\end{array}$} & \multicolumn{2}{c|}{$\begin{array}{c}\mathbf{9 5 \%} \text { Confidence } \\
\text { Interval }\end{array}$} \\
\cline { 3 - 4 } & & Lower & Upper \\
\hline Dietary control & 2.245 & .906 & 5.563 \\
\hline Medical adherence & 3.231 & 1.357 & 7.693 \\
\hline Blood glucose monitoring & .352 & .147 & .844 \\
\hline Physical activity & .323 & .131 & .796 \\
\hline Physician contact & 6.525 & 1.755 & 24.256 \\
\hline Overall & .360 & .091 & 1.428 \\
\hline
\end{tabular}

For Dietary control the odds ratio was 2.245 with C.I 95\% (Lower=0.90, Upper=5.56).For Medical adherence the odds ratio was 3.231with C.I 95\% (Lower=1.35, Upper=7.69). For Blood glucose monitoring the odds ratio was 0.352 with C.I 95\% (Lower=0.14, Upper $=0.84$ ). For Physical activity the odds ratio was 0.323 with C.I 95\% (Lower=0.13, Upper=0.79). For Physician contact the odds ratio was 6.525 with C.I 95\% (Lower=1.75, Upper=24.25). For Overall the odds ratio was 0.360 with C.I $95 \%$ (Lower=0.09, Upper=1.42).

Table No 6: Odds Ratio Score between DSSE and Domain Wise DSMQ

\begin{tabular}{|l|c|c|c|}
\hline \multicolumn{1}{|c|}{ Diabetes self efficacy } & \multirow{2}{*}{ P Value } & \multicolumn{2}{|c|}{$\begin{array}{c}\mathbf{9 5 \%} \text { Confidence } \\
\text { Interval }\end{array}$} \\
\cline { 3 - 4 } & & Lower & Upper \\
\hline Dietary control & .962 & .297 & 3.109 \\
\hline Medical adherence & 3.781 & 1.103 & 12.958 \\
\hline Blood glucose monitoring & 1.151 & .373 & 3.557 \\
\hline Physical activity & 1.304 & .406 & 4.194 \\
\hline Physician contact & .868 & .219 & 3.433 \\
\hline Overall & .985 & .193 & 5.029 \\
\hline
\end{tabular}

For Dietary control the odds ratio was 0.962 with C.I 95\% (Lower=0.297, Upper=3.109). For Medical adherence the odds ratio was 3.781 with C.I 95\% (Lower=1.10, Upper=12.9). For Blood glucose monitoring the odds ratio was 1.151 with C.I 95\% (Lower=0.373, Upper=3.557). For Physical activity the odds ratio was 1.304 with C.I 95\% (Lower=0.406, Upper=4.19).For Physician contact the odds ratio was 0.868 with C.I $95 \%$ (Lower $=0.219$, Upper $=3.43$ ). For Overall the odds ratio was 0.985 with C.I $95 \%$ (Lower=0.19, Upper=5.029).

Limitations of the study: The study was limited to find the association between impulse control, Diabetes specific self efficacy and Diabetes self-management. Data was collected from only 91 subjects and the study was conducted in only one hospital.

\section{Acknowledgement: None}

\section{Conflict of Interest: None}

\section{Source of Funding: None}

Ethical Approval: Approved

\section{REFERENCES}

1. Diabetes is an international medical problem and people with diabetes often have multiple healthcare needs requiring assessment and various holistic interventions.

https://en.wikipedia.org/wiki/Self-efficacy

2. Viswanathan Vijay \& Rao V Narayan, Future Medicine Ltd Diabetes Manage. (2013) 3(1), 31-40. https://www.linkedin.com/in/vviswanathan 
Ambareesh Patil et.al. Explore the relationship between impulse control, diabetes specific self- efficacy and diabetes management among young adults with Diabetes Mellitus

3. The IDF Diabetes Atlas Ninth edition 2019, www.diabetesatlas.org.

4. Impulse Control Disorder \& Addiction: Causes, Symptoms \& Treatment. American Addiction Centers. 2021 Available from: https://americanaddictioncenters.org/cooccurring-disorders/impulsecontrol-disorder

5. Kartal A, Calli D. The relationship between self-efficacy of diabetes management and well-being in patients with type 2 diabetes. Nigerian Journal of Clinical Practice. 2021; 24(3):393.

6. The prevalence of type 2 diabetes in adolescents and young adults is dramatically increasing.https://www.thelancet.com/journ als/landia/article/PIIS2213-8587(17)301869

7. Kalyan Ray, New Delhi, Mar 15, 2016, DHNS:, MAR 16 2016, 01:36 ISTUPDATED: MAR 16 2016, 01:44 IST.https://www.deccanherald.com/content/ 534795/karnataka-high-diabetes-risk.html.
8. Diabetes in India, Cadi Research. Retrieved 2020-04-29.

https://en.wikipedia.org/wiki/Diabetes_in_I ndia

9. Sharma N. Government survey found $11.8 \%$ prevalence of diabetes in India [Internet]. mint. 2021 [cited 11 July 2021]. Available from:

https://www.livemint.com/science/health/go vernment-survey-found-11-8-prevalence-ofdiabetes-in-india-11570702665713.html

How to cite this article: Ambareesh Patil, Deelip S Natekar, Utalbasha Dhandargi. Explore the relationship between impulse control, diabetes specific self- efficacy and diabetes management among young adults with diabetes mellitus. International Journal of Science \& Healthcare Research. 2022; 7(1): 81-87. DOI: https:// doi.org/10.52403/ijshr.20220114 